\title{
Original Article \\ Polysaccharide of Radix Pseudostellariae Improves Chronic Fatigue Syndrome Induced by Poly I:C in Mice
}

\author{
Rong Sheng,, Xianxiang Xu, ${ }^{1}$ Qin Tang, ${ }^{1}$ Difei Bian, ${ }^{1}$ Ying Li, ${ }^{1}$ Cheng Qian, ${ }^{1}$ Xin He, \\ Xinghua Gao, ${ }^{1}$ Rong Pan, ${ }^{1}$ Chong Wang, ${ }^{1}$ Yubin Luo, ${ }^{1}$ Yufeng Xia, ${ }^{2}$ and Yue Dai ${ }^{1}$ \\ ${ }^{1}$ Department of Pharmacology of Chinese Materia Medica, China Pharmaceutical University, Nanjing 210009, China
${ }^{2}$ Department of Chinese Materia Medica Analysis, China Pharmaceutical University, Nanjing 210009, China \\ Correspondence should be addressed to Yue Dai, yuedaicpu@hotmail.com
}

Received 13 January 2009; Accepted 13 November 2009

Copyright (C) 2011 Rong Sheng et al. This is an open access article distributed under the Creative Commons Attribution License, which permits unrestricted use, distribution, and reproduction in any medium, provided the original work is properly cited.

\begin{abstract}
Radix Pseudostellariae is used as a tonic drug in traditional Chinese medicine with immunomodulating and anti-fatigue activities, and the polysaccharide is considered as the main active component. The purpose of this study is to examine the effect of the polysaccharide isolated from Radix Pseudostellariae (PRP) on mouse chronic fatigue syndrome (CFS) induced by intraperitoneal injection of polyriboinosinic:polyribocytidylic acid (poly I:C), a double-stranded synthetic RNA. It has shown that the fatigue symptom of mice lasted at least 1 week as evaluated by forced swimming time. PRP $\left(100,200,400 \mathrm{mg} \mathrm{kg}^{-1}\right)$, orally administered 3 days before poly I:C injection, showed dose-dependent anti-fatigue effects. In addition, poly I:C led to evident alternations in neuroendocrine and immune systems of mice, such as reduced spontaneous activity and learning ability, declined serum level of corticosterone, increased weight indexes and $\mathrm{T}$ lymphocyte numbers in thymuses and spleens, and increased $\mathrm{CD} 4^{+} / \mathrm{CD} 8^{+}$ratio but decreased proliferation ability of T lymphocytes in spleens. PRP alleviated the abnormalities caused by poly I:C, and restored the function of hosts to normal conditions. The findings suggest that PRP is beneficial to CFS, and the underlying mechanisms of action involve neuroendocrine and immune systems.
\end{abstract}

\section{Introduction}

Chronic fatigue syndrome (CFS) was first defined in 1988 by the US Centers for Disease Control and Prevention as unexplained disabling fatigue lasting more than 6 months, together with a combination of non-specific accompanying symptoms [1]. CFS patients usually experience substantial reductions in occupational, educational and social functions, which collectively hamper the quality of life [2]. In addition, CFS is a debilitating syndrome with a cluster of multi-system dysfunctions [3], mainly involving the neuroendocrine and immune systems, and usually influencing other systems as well [4-7]. The pathogenesis of CFS probably includes immune system abnormalities, chronic immune activation, hypothalamic-pituitary-adrenal (HPA) axis dysfunction, brain anomalies, emotional stress and exogenous insults [8]. However, little is known about the underlying mechanisms of the fatigue symptoms in any clinical condition. Viral infection is of vital importance to CFS as considered from an etiologic aspect. Emotional stress appears to be important as well, as it impairs the normal function of the immune system against infections. Furthermore, emotional stress has been shown to determine, whether or not, an individual develops fatigue symptom upon virus infection, and can lead to the activation of the HPA axis. Likewise, a number of studies have focused on altered immune function in CFS, and immune function anomalies have been considered as potential explanations for the symptom complex or as possible predisposing factors for altered responses to infections.

Polyriboinosinic:polyribocytidylic acid (poly I:C), a double-stranded synthetic RNA, is frequently applied in animal experiments to mimic a condition of viral infection. Recently, Katafuchi et al. [9] reported that intraperitoneal injection of poly I:C in rats resulted in a significant and persistent reduction of spontaneous running wheel activity, which could be considered as an animal model of immunologically chronic fatigue with mechanisms closely related to the neuronal-endocrine-immune interactions.

Alternative medicines including Traditional Chinese Medicine have advantages of being effective to alleviate symptoms of CFS such as fatigue, disordered sleep, cognitive 
handicap and other complex complaints with minor side effects. The underlying mechanisms mainly include regulating immune function, adjusting abnormalities in the HPA axis and antioxidation [10]. Pinus pinaste bark could alleviate fatigue and activate the endogenous antioxidant enzyme system [11]. Angelica sinensis and Matricaria chamomilla extracts could ameliorate fatigue and sleep disturbances [12]. Panax ginseng has been used for centuries in Oriental folk medicine against fatigue. It could elevate movement ability and resist against CNS fatigue in mice [13]. Clinically, Ginseng could alleviate chronic fatigue, reducing fatigue severity and curtailing fatigue duration [14]. Acanthopanacis senticosus or Siberian ginseng showed ameliorating effects on CFS in a placebo-controlled clinical study [15]. Crataegus oxyacantha showed a significant increase in exercise time and an improvement in life quality in a three month placebocontrolled, randomized, double-blind trial [16]. Eucommia ulmoides leaves enhanced the 3-hydroxy-acyl-CoA dehydrogenase specific activity and lactate dehydrogenase specific activity in the skeletal muscle, suggesting that exercising and intaking of the leaf cooperatively could decrease the possibility of lactate accumulation in skeletal muscle and that the administration of E. ulmoides leaves along with low intensity training can enhance the ability of a muscle to resist fatigue [17] Rhodiola rosea is used as a central stimulant, antidepressant and antifatigue drug. Rhodiola rosea extract showed a significant improvement in the total mental performance [18] Oryza sativa, Gentiana lutea symphyandra and Trichopus zeylanicus-treated mice performed a better physical endurance in forced swimming tests [19-21]. Withania somnifera, Quercetin and Hypericum perforatum $L$. have been used for the treatment of CFS with the purpose of reducing lipid peroxidation, restoring the glutathione levels and increasing the superoxide dismutase levels in the brains of CFS mice [22]. Ginkgo biloba and Vaccinium myrtillus (bilberry) have also been reported containing beneficial antioxidants for CFS [23].

Radix Pseudostellariae, the roots of Pseudostellaria heterophylla, is widely used as a tonic drug in China for the treatment of splenic asthenia syndrome, which partially manifests features of CFS. Macromolecule polysaccharides have long been recognized as the main active component of Radix Pseudostellariae [24]. They possess antiinfectious, antioxidative and immunomodulating activities [25-27], suggesting that they might be beneficial to CFS. In the present study, the antifatigue effects of the polysaccharides were evaluated in poly I:C-induced mouse model of CFS. The mechanisms of action were addressed in terms of neurological, endocrine and immune regulations.

\section{Materials and Methods}

2.1. Chemicals and Reagents. Poly I:C was purchased from Guangdong BangMin Pharmaceutical Co., Ltd., Guangdong, China. Corticosterone radioimmunity kit was purchased from Beijing PuerWeiye Biotechnology, Ltd., Beijing, China. Concanavalin A (Con A) was purchased from Sigma, USA. Phycoerythrin (PE) antimouse CD4 (L3T4, Cat\#: BM0404), PE antimouse CD8 (Lyt-2, Cat\#: EM0804), fluorescein isothiocyanate (FITC) antimouse CD3 (Cat\#: EM0301) and lysing solution were purchased from MultiSciences Biotech Co., Ltd., Shanghai, China.

2.2. Animals. Male ICR mice ( $18-22 \mathrm{~g})$ were purchased from the experimental animal centre of China Pharmaceutical University. The animals were housed with free access to standard laboratory chow and water at $23 \pm 2^{\circ} \mathrm{C}$ with a dark and light cycle of $12 \mathrm{~h}$ each. Animal experiments were conducted in accordance with current ethical regulations for institutional animal care and use of China Pharmaceutical University. The study was approved by the Institutional Ethical Committee of China Pharmaceutical University.

2.3. Preparation of $P R P$. Radix Pseudostellariae was purchased from Anhui Province, China, and was authenticated by Professor Mian Zhang, China Pharmaceutical University. Powdered crude drugs $(400 \mathrm{~g})$ were extracted three times by refluxing with $80 \%$ ethanol $(1 \mathrm{~L})$ at $90^{\circ} \mathrm{C}$ for $2 \sim 3 \mathrm{~h}$ each time. After filtration, the gruffs were extracted again for three times with water $(1.5 \mathrm{~L})$ at $90^{\circ} \mathrm{C}$ for $2-3 \mathrm{~h}$ each time. The extracted solution was condensed to $400 \mathrm{~mL}$ and deproteinated by applying the Sevag method. The solution was then added to absolute ethyl alcohol until the ethanol concentration was $80 \%$ and kept overnight, followed by filtration. The precipitate was dissolved with water $(100 \mathrm{~mL})$ and then added absolute ethyl alcohol until the ethanol concentration was $80 \%$, filtrated and repeated once again. The precipitate was washed with $95 \%$ ethanol, absolute ethyl alcohol and acetone by turns, and then dried at $50^{\circ} \mathrm{C}$, leaving an ivory white powder. The yield ratio of the polysaccharides in the dried roots was $2.13 \%$, and the purity was $72.65 \%$ as measured by a phenol-sulfuric acid colorimetric method with glucose as a reference. The crude dried PRP was dissolved in distilled water just before use.

2.4. Therapy Regimen. Fifty mice were randomly divided into five groups: 1: normal; 2: control; 3: PRP (100 $\left.\mathrm{mg} \mathrm{kg}^{-1}\right)$; 4: PRP (200 $\left.\mathrm{mg} \mathrm{kg}^{-1}\right)$; 5: PRP ( $\left.400 \mathrm{mg} \mathrm{kg}^{-1}\right)$. PRP was orally administered with a volume of $0.2 \mathrm{~mL} / 10 \mathrm{~g}$ body weight at 8:00 am for consecutive 17 days. Normal and control mice were given orally an equal volume of vehicle. On day 4 , except the mice in normal group, all mice were intraperitoneally injected poly I:C $\left(5 \mathrm{mg} \mathrm{kg}^{-1}\right)$ to induce CFS.

2.5. Forced Swimming Test. On day 1, 4, 7, 10 and 13 after injection of poly I:C, forced swimming test was carried out in a plastic pool $(48 \times 36 \times 29 \mathrm{~cm})$. The water depth and temperature were $20 \mathrm{~cm}$ and $22 \pm 1^{\circ} \mathrm{C}$, respectively. Mice were loaded $5 \%$ of the body weight of lead threads at the bases of the tails. They were then forced to swim until fatigue, defined as failure to rise to the surface of the water to breathe within an 8-s period. The time until fatigue was recorded.

2.6. Spontaneous Activity. On day 3 before injection, day 1 and 7 after injection of poly I:C, open field test was performed to evaluate the locomotive and explorative behavior in a novel circumstance. The open field apparatus was 
a cylindrical box (diameter: $30 \mathrm{~cm}$, height: $20 \mathrm{~cm}$ ), which was divided into 19 equal grids on the floor. Mice were placed individually on the centre of the apparatus, and were allowed to move freely for $5 \mathrm{~min}$. During the test, the total number of cross points was manually recorded.

2.7. Learning Ability. On day 14 after injection of poly I:C, step-down test was performed to examine the learning ability of mice. The apparatus consisted of a transparent acrylic chamber with an electrifiable grid floor. A rubber platform (diameter: $4.5 \mathrm{~cm}$, height: $4.5 \mathrm{~cm}$ ) was placed on the grid floor. Mice were allowed to move freely in the chamber for 3 min without current in the electrifiable grid floor. In the following $5 \mathrm{~min}$, mice were put on the platform with current in the electrifiable grid floor. If they stepped down from the platform ("error trial"), they were punished by an electric foot shock $(36 \mathrm{~V}, \mathrm{AC})$. The error number was recorded as the final grade for the learning ability test.

2.8. Assay of Serum Corticosterone Level. On day 14 after poly I:C injection, mice of all groups were sacrificed, and the peripheral blood samples $(0.2 \mathrm{~mL}$ per mouse $)$ were collected. The blood samples were centrifuged for $10 \mathrm{~min}$ at $4^{\circ} \mathrm{C}, 3000 \mathrm{rmin}^{-1}$. Sera were stored at $-70^{\circ} \mathrm{C}$ until assay. Corticosterone level was measured by radioimmunoassay according to the manufacturer's instructions.

2.9. $\mathrm{CD}^{+} \mathrm{T}$ and $\mathrm{CD} 8^{+}$Tlymphocytes in Peripheral Blood. On day 14 after poly I:C injection, anticoagulated blood $(0.2 \mathrm{~mL}$ per mouse) was collected, and stained with $5 \mu \mathrm{L}$ of PE antimouse CD4, PE antimouse CD8 and FITC antimouse CD3, respectively. The blood was incubated in the dark at $4^{\circ} \mathrm{C}$ for $1 \mathrm{~h}$. Then, the lysing solution $(2 \mathrm{~mL})$ was added to lyse erythrocytes. The mixtures were incubated in the dark at room temperature for $30 \mathrm{~min}$, and centrifuged at $4^{\circ} \mathrm{C}$ for $1500 \mathrm{rmin}^{-1}$. Then, they were washed with $2 \mathrm{~mL}$ PBS, and dissolved with PBS $(500 \mu \mathrm{L})$. The cells were analyzed on a flow cytometer, using cell quest software.

2.10. Weighing and Histological Analysis of Immune Organs. On day 14 after poly I:C injection, spleens and thymuses of mice in each group were removed and weighed, and the weight indexes $\left(\mathrm{mg} \mathrm{g}^{-1}\right.$ b.w.) were calculated. Then they were fixed in formaldehyde, sectioned and embedded in paraffin, and sliced for hematoxylin and eosin staining. Several parameters, including peripheral cortex thickness of thymus, numbers of splenic corpuscles and periarterial lymphatic sheaths, splenic sinusoid and splenic cord size, were evaluated in the histological analysis.

2.11. Spleen Cell Proliferation Assay. On day 14 after poly $\mathrm{I}: \mathrm{C}$ injection, spleens of six mice in each group were gently homogenized and repeatedly pipetted to attain a single splenocyte suspension. The cells were washed twice with ice-cold PBS and separated by nylon mesh (cell viability $>$ $95 \%$ ), and then seeded in 96-well culture plates at a final concentration of $5 \times 10^{6}$ cells/well in a RPMI-1640 medium supplemented with $10 \%$ FBS. Splenocytes, treated with or

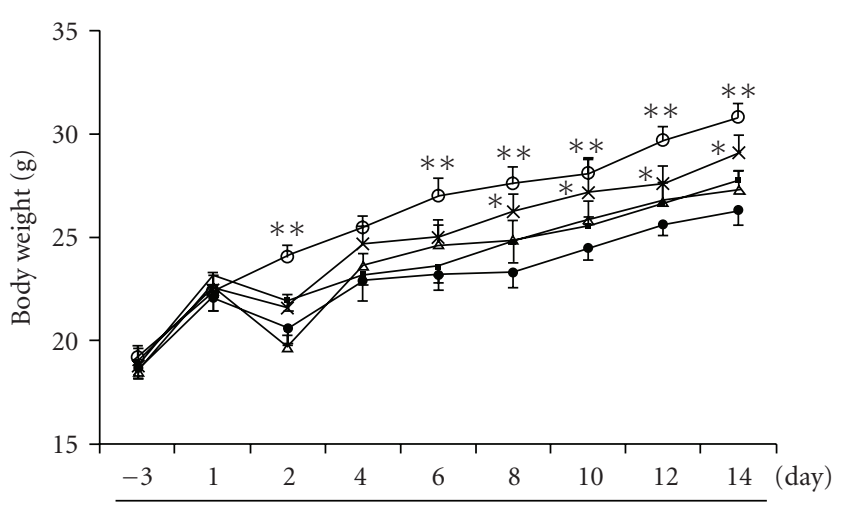

Days before and after poly I:C injection

$$
\begin{array}{ll}
\rightarrow \text { Normal } & \rightarrow \text { PRP } 200 \mathrm{mg} / \mathrm{kg} \\
\rightarrow \text { Control } & \rightarrow \text { PRP } 400 \mathrm{mg} / \mathrm{kg} \\
\triangle \text { PRP } 100 \mathrm{mg} / \mathrm{kg} &
\end{array}
$$

FIGURE 1: Effect of PRP on the body weights of mice treated with poly I:C. PRP was administered orally from 3 days before poly I:C injection for 17 days. Data are expressed as means \pm SEM $(n=10)$. ${ }^{*} P<.05 ;{ }^{*} P<.01$ versus control.

without mitogen Con A $\left(5 \mu \mathrm{g} \mathrm{mL}^{-1}\right)$, were incubated for $68 \mathrm{~h}$ at $37^{\circ} \mathrm{C}$ in a $5 \% \mathrm{CO}_{2}$ incubator. Subsequently, $20 \mu \mathrm{L}$ of MTT (3-(4,5-dimethylthiazol-2-yl)-2,5-diphenyltetrazolium bromide) $\left(0.5 \mathrm{mg} \mathrm{mL}^{-1}\right)$ was added into each well, and the cells were incubated for another $4 \mathrm{~h}$. After that, the supernatant was removed and the formazan crystals were dissolved using DMSO (dimethyl sulphoxide) $(150 \mu \mathrm{L})$. The absorbance at $570 \mathrm{~nm}$ was read with a Model 1500 Multiskan spectrum microplate Reader (Thermo, Waltham, MA, USA).

2.12. Statistics. All values were expressed as mean \pm SEM. Data were statistically analyzed by ANOVA followed by post hoc Tukey test. Differences were considered significant at $P<.05$.

\section{Results}

3.1. PRP Increased the Body Weights of Mice. Body weight, an indicator of health status, was measured every other day. Poly I:C injection resulted in a rapid and persistent decrease in the body weights of mice (Figure 1). PRP (100, 200, $400 \mathrm{mg} \mathrm{kg}^{-1}$ ) dose-dependently increased the body weights of mice during the 2 weeks after the injection of poly I:C. Statistically significant increase was observed in PRP (400 $\mathrm{mg} \mathrm{kg}^{-1}$ )-treated group from day 8 to 14 .

3.2. Anti-Fatigue Activity of PRP. The forced swimming time of mice was considered as an indicator of fatigue. During 13 days of trial period, the forced swimming time of normal mice was within 80 to $90 \mathrm{~min}$. At $6 \mathrm{~h}$ after poly I:C injection, the average forced swimming time of control group decreased sharply, and lasted at least for 1 week. From the second week, it gradually recovered, and yet, not reached the baseline level until day 13. PRP (100, 200, $\left.400 \mathrm{mg} \mathrm{kg}^{-1}\right)$ 

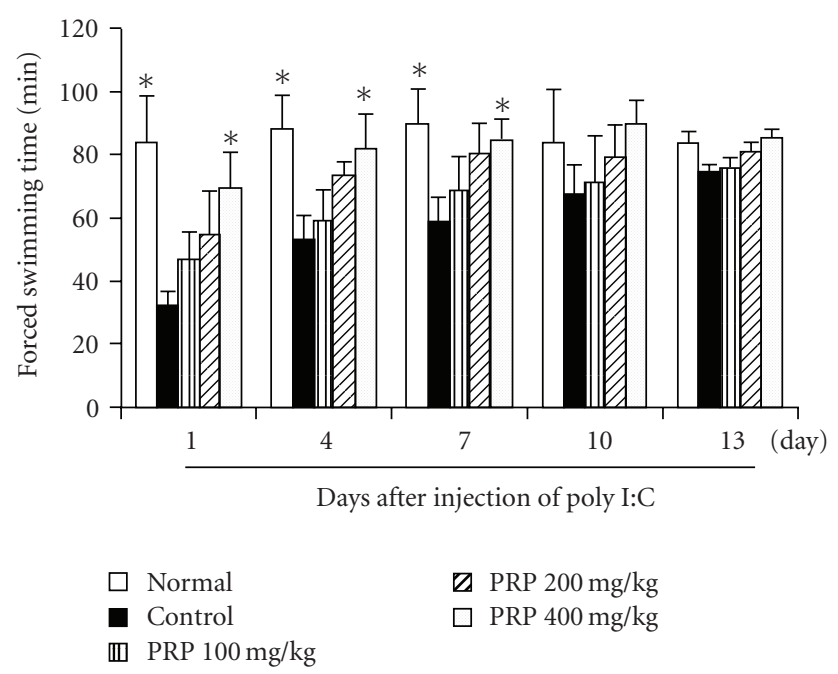

FIgURE 2: Effect of PRP on chronic fatigue induced by poly I:C in mice. PRP was administered orally from 3 days before poly I:C injection for 17 days. Forced swimming test was performed at indicated days. Data are expressed as means \pm SEM $(n=10)$. ${ }^{*} P<.05$ versus control.

dose-dependently prolonged the forced swimming time during the full experiment period. Especially, PRP $\left(400 \mathrm{mg} \mathrm{kg}^{-1}\right)$ showed a statistically significant effect in the first week (Figure 2).

3.3. PRP Increased Spontaneous Activity. Before and after poly I:C injection, the spontaneous activity of five groups of mice was examined by open field test. The results were presented in Figure 3. Baseline levels of spontaneous activities were of the similar level among all groups without significant differences. At $4 \mathrm{~h}$ after poly I:C injection, spontaneous activity of mice in control group decreased significantly compared with that of the normal group. PRP $\left(100,200,400 \mathrm{mg} \mathrm{kg}^{-1}\right)$ showed a dose-dependent increase in spontaneous activity. On day 7, the spontaneous activities of mice in both control and PRP-treated groups restored almost to the baseline level.

3.4. PRP Improved the Learning Ability. On day 14 after poly $\mathrm{I}: \mathrm{C}$ injection, the step-down latency of passive avoidance response (number of errors) of mice in control group was apparently longer than that of normal group, suggesting that poly I:C resulted in decline of learning ability. PRP (100, $200,400 \mathrm{mg} \mathrm{kg}^{-1}$ ) treatment decreased the number of errors of mice in a dose-dependent manner. Statistically significant improvements of learning ability were displayed in PRP (200, $400 \mathrm{mg} \mathrm{kg}^{-1}$ )-treated groups (Figure 4).

3.5. PRP Increased the Serum Corticosterone Level. As shown in Figure 5, the average serum corticosterone level of mice in control group was significantly decreased in comparison with normal group on day 14 after poly I:C treatment. PRP $\left(100,200,400 \mathrm{mg} \mathrm{kg}^{-1}\right)$ dose-dependently elevated the
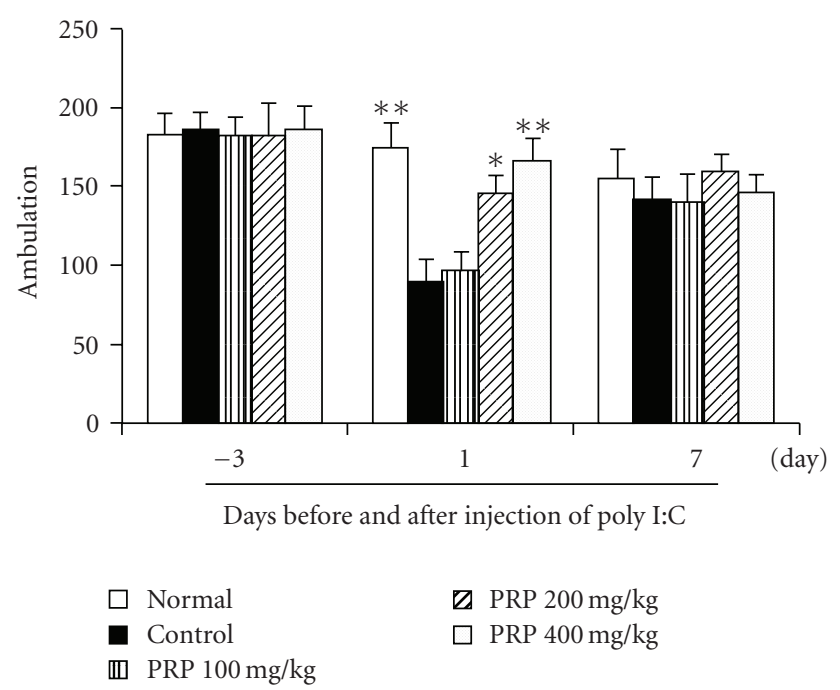

FIGURE 3: Effect of PRP on spontaneous activity in mice treated with poly I:C. Mice were placed individually on the center of the apparatus, and were allowed to move freely for $5 \mathrm{~min}$. The total number of cross points was manually recorded at indicated days after injection of poly I:C. PRP was administered orally from 3 days before poly I:C injection for 17 days. Data are expressed as means \pm $\operatorname{SEM}(n=10) .{ }^{*} P<.05,{ }^{* *} P<.01$ versus control.

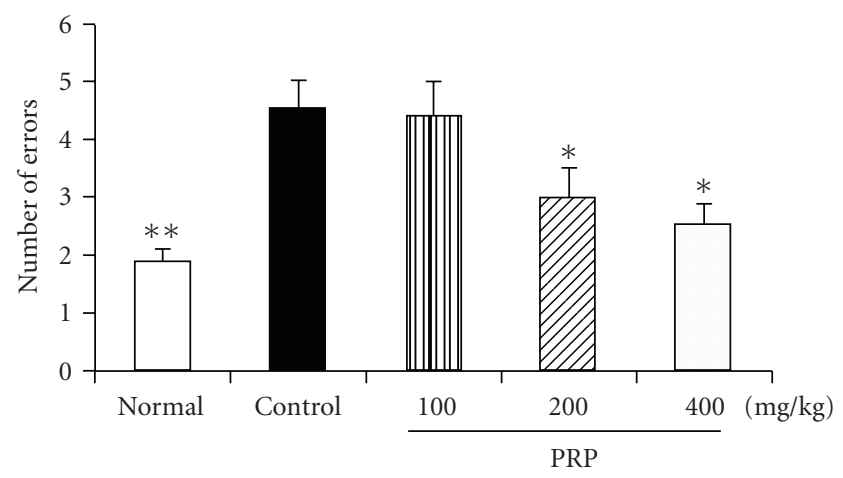

FIGURE 4: Effect of PRP on learning ability in mice treated with poly I:C. The error number of the learning training was recorded as the learning grade on Day 14 after injection of poly I:C. PRP was administered orally from 3 days before poly I:C injection for 17 days. Data are expressed as means \pm SEM $(n=10) .{ }^{*} P<.05$ versus control.

corticosterone level, and completely reversed the decrease of serum corticosterone at the dose of $400 \mathrm{mg} \mathrm{kg}^{-1}$.

3.6. Impacts of PRP on Immune Organ Index. Poly I:C treatment resulted in the increases of both thymus and spleen indexes of mice. PRP $\left(100,200,400 \mathrm{mg} \mathrm{kg}^{-1}\right)$ did not affect the thymus index, but dose-dependently decreased the spleen index. The spleen index of mice in PRP $\left(400 \mathrm{mg} \mathrm{kg}^{-1}\right)$ treated group was close to the normal value on day 14 after poly I:C injection (Figure 6).

3.7. Histological Findings of Immune Organs. Each thymus lobule has a peripheral cortex consisting of a dense population of thymocytes which surround the lightly stained 


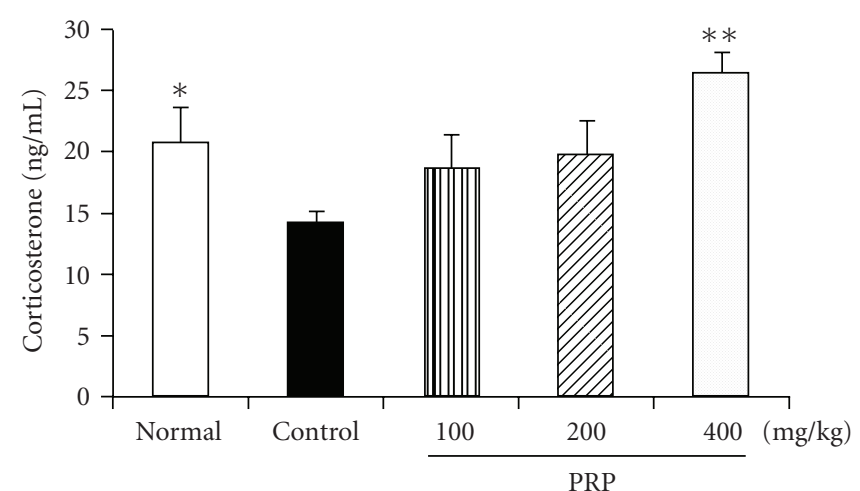

FIGURE 5: Effect of PRP on serum corticosterone level in mice treated with poly I:C. Peripheral blood samples were collected with $0.2 \mathrm{~mL}$ per mouse on Day 14 after injection of poly I:C. Serum corticosterone level was measured by radioimmunoassay assay. PRP was administered orally from 3 days before poly I:C injection for 17 days. Data are expressed as means \pm SEM $(n=10) .{ }^{*} P<.05$, ${ }^{* *} P<.01$ versus control.

central medulla. After treated with poly I:C, the thickness and the thymocyte numbers in the peripheral cortex of mouse thymus were obviously increased together with a compacted arrangement of thymocytes. PRP (100, 200, $400 \mathrm{mg} \mathrm{kg}^{-1}$ ) reduced the thymocyte population to normal level (Figure 7).

There are white pulp, red pulp and marginal zone in spleen parenchyma. White pulp consists of splenic corpuscles and periarterial lymphatic sheaths. Red pulp consists of splenic sinusoid and splenic cord. Compared with normal group, size of both splenic corpuscles in white pulp and periarterial lymphatic sheaths in red pulp were obviously increased in control group, suggesting that poly I:C led to increase the Tlymphocyte population in spleens. In addition, splenic sinusoid in red pulp distended and engorged slightly in control group. PRP $\left(100,200,400 \mathrm{mg} \mathrm{kg}^{-1}\right)$ ameliorated the histological changes in spleens to different degrees (Figure 8).

3.8. PRP Regulated the Ratio of $\mathrm{CD}^{+}$and $\mathrm{CD} 8^{+} \mathrm{T}$ Lymphocytes in Peripheral Blood. Peripheral blood of mice was collected on day 14 after poly I:C treatment for the detection of $\mathrm{T}$ lymphocyte population using flow cytometry analysis. It was shown that poly I:C resulted in a remarkable increase of $\mathrm{CD}^{+} / \mathrm{CD}^{+}$ratio by increasing $\mathrm{CD}^{+} \mathrm{T}$ lymphocyte percentage and decreasing $\mathrm{CD} 8^{+} \mathrm{T}$ lymphocyte percentage. PRP $\left(100,200,400 \mathrm{mg} \mathrm{kg}^{-1}\right)$ modulated the percentages of the two types of lymphocytes and restored the $\mathrm{CD} 4^{+} / \mathrm{CD}^{+}$ ratio to normal (Table 1 ).

3.9. PRP Increased the Proliferation Ability of Spleen T Lymphocytes. The proliferation of mouse spleen T lymphocytes was induced by Con A in vitro. As shown in Figure 9, the proliferation ability of $\mathrm{T}$ lymphocytes in poly I:C-treated group was significantly reduced. PRP at doses of 100, 200 and $400 \mathrm{mg} \mathrm{kg}^{-1}$ promoted the proliferation ability, and the
TABLE 1: Effect of PRP on $\mathrm{CD}^{+}$and $\mathrm{CD}^{+} \mathrm{T}$ lymphocyte populations in peripheral blood of mice treated with poly I:C.

\begin{tabular}{lcccc}
\hline Groups & $\begin{array}{c}\text { Dose } \\
\left(\mathrm{mg} \mathrm{kg}^{-1}\right)\end{array}$ & $\begin{array}{c}\mathrm{CD}^{+} / \mathrm{CD}^{+} \\
(\%)\end{array}$ & $\begin{array}{c}\mathrm{CD}^{+} / \mathrm{CD}^{+} \\
(\%)\end{array}$ & $\mathrm{CD}^{+} / \mathrm{CD}^{+}$ \\
\hline Normal & - & $66.8 \pm 1.1^{*}$ & $29.8 \pm 4.0$ & $2.4 \pm 0.3^{*}$ \\
Control & - & $74.2 \pm 2.2$ & $24.1 \pm 1.6$ & $3.5 \pm 0.2$ \\
& 100 & $72.3 \pm 0.7$ & $24.7 \pm 1.2$ & $2.9 \pm 0.1$ \\
PRP & 200 & $71.3 \pm 3.0$ & $25.4 \pm 2.0$ & $2.9 \pm 0.3$ \\
& 400 & $71.5 \pm 1.1$ & $26.1 \pm 0.7$ & $2.7 \pm 0.1^{*}$ \\
\hline
\end{tabular}

Anticoagulated blood $0.2 \mathrm{~mL}$ of each mouse was collected on day 14 after injection of poly I:C. The cell populations were analyzed by flow cytometry. Data are expressed as means $\pm \operatorname{SEM}(n=5) .{ }^{*} P<.05$ versus control.

proliferation index in PRP $\left(400 \mathrm{mg} \mathrm{kg}^{-1}\right)$-treated group was close to that of normal group.

\section{Discussion}

CFS is characterized by clinically unexplained fatigue, lasted at least for six months, which is not the outcome of ongoing exertion and is not substantially alleviated by rest. Although the exact pathogenesis of CFS remains unclear, current hypotheses postulate that special virus infection and immune dysfunction relevant to infection are contributed to the occurrence of CFS. For experimental purpose, several animal models of CFS have been established by injecting the bacterial antigen from Corynebacterium parvum and Brucella abortus [28-30], injection of poly I:C, and 15-day exposure to forced swimming [31]. Among these models mentioned above, poly I:C- or B. abortus antigen-induced fatigue is able to persist for more than 1 week in contrast to the short duration induced by C. parvum antigen. In addition, as CFS is not the result of ongoing exertion, fatigue due to forced swimming for 15 days seems to be an improper model of CFS. Therefore, in the present study, we evaluated the antiCFS effect of PRP using poly I:C model, and explored the underlying mechanisms of PRP in terms of neuroendocrine and immune modulation.

Forced swimming time and spontaneous running wheel activity are usually adopted to represent the physical work capacity and fatigue condition of animals. In the current study, the forced swimming time of normal mice was nearly stable during the 2 weeks. Intraperitoneal injection of poly I:C resulted in a persistent decline of mouse swimming time, indicating that it can induce chronic fatigue condition in mice as in rats [9]. PRP, orally administered prior to poly I:C injection, prolonged mouse swimming time in a dose-dependent manner. Further, we found that poly I:C treatment led to a marked reduction of spontaneous activity of mice in the open field test by near 50\% as compared with the normal group, and PRP exhibited ameliorating effect on the spontaneous activity in poly I:C-treated mice. The findings demonstrated that PRP had beneficial effects on chronic fatigue.

It is generally accepted that the persistent fatigue is not due to peripheral problems such as muscular weakness and muscle or joint pain, but involves complex central 


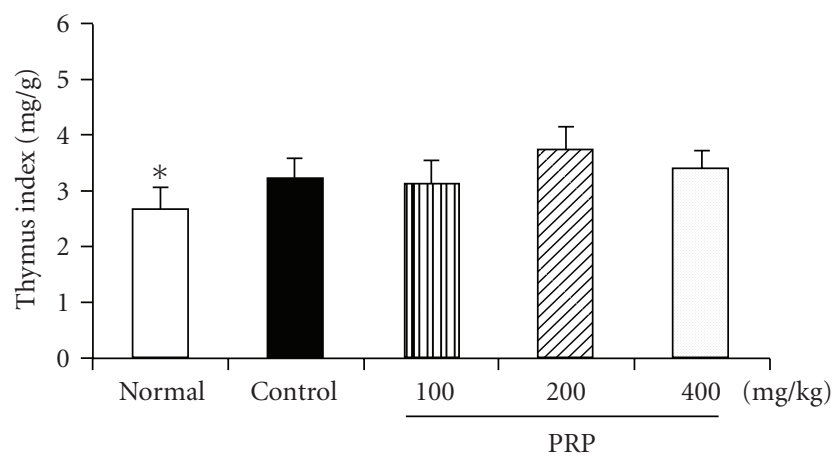

(a)

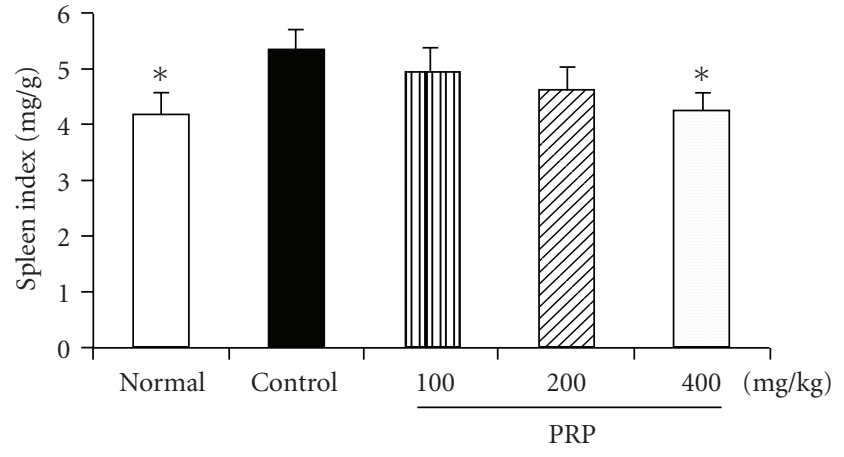

(b)

FIGURE 6: Effect of PRP on immune organ weight of mice treated with poly I:C. Mouse thymuses and spleens were removed and weighed on Day 14 after injection of poly I:C. Thymus and spleen indexes were calculated. PRP was administered orally from 3 days before poly I:C injection for 17 days. Data are expressed as means \pm SEM $(n=10) .{ }^{*} P<.05$ versus control.

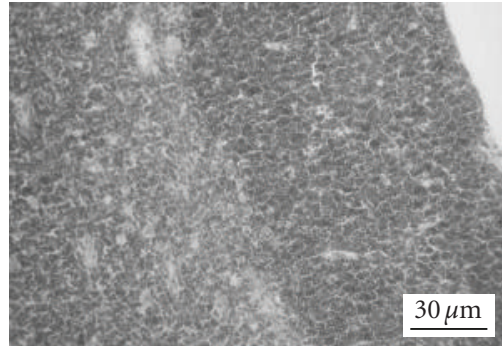

Normal

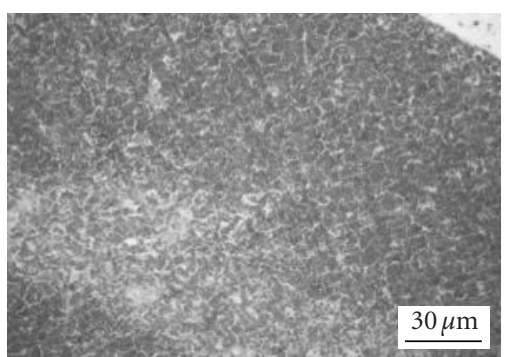

Control

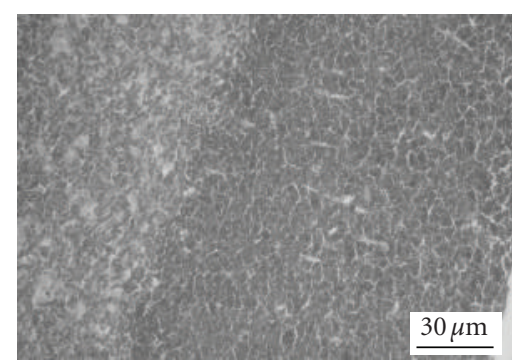

PRP 100 mg/kg

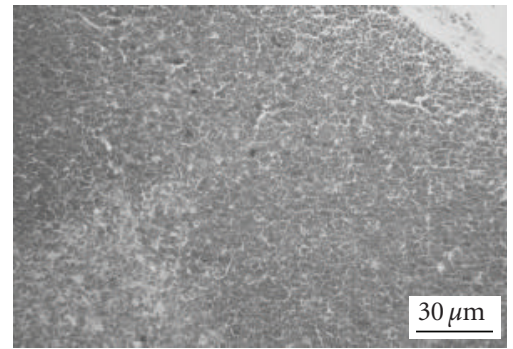

PRP 200 mg/kg

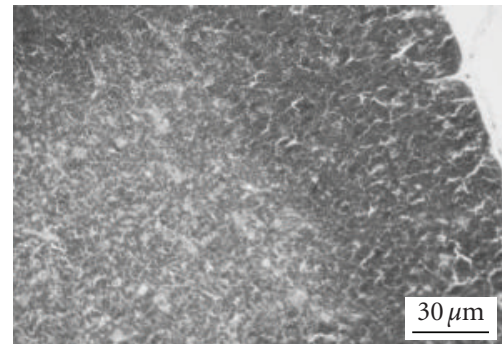

PRP 400 mg/kg

FIGURE 7: Representative histological changes in thymuses (hematoxylin and eosin, H\&E, $\times 100$ ). Thymuses were removed on Day 14 after poly I:C injection. Peripheral cortex thickness of thymus was evaluated.

mechanisms [32]. Under the condition of chronic fatigue, cytokines produced in the brain exert various central actions, including activation of sympathetic nervous system and hypothalamic-pituitary axis, impairment of learning memory and influence of peripheral cellular immunity [33]. It has been reported that not only personal activity reduction, but cognitive disturbances are also exhibited in CFS patients [2]. Poly I:C is thought to induce central fatigue through modulating IFN- $\alpha$ and 5-HT expressions in the brain [34]. In the current study, it remarkably impaired the cognitive and learning ability of mice in the step down test. PRP could dose-dependently reverse the learning ability decline caused by poly I:C. Since PRP is a soluble micromolecule, it is probably difficult to cross the blood-brain barrier (BBB) and activate gliacytes directly. PRP may passively cross the BBB at "leaky" regions where the BBB is not intact, such as the circumventricular organs (CVO's), and directly act on endothelial cells of brain vasculature or glial cells in the CVO's, inducing the synthesis/release of central cytokines. On the other hand, PRP may activate immune system to release a lot of cytokines, which affect central nervous system indirectly.

The HPA axis carries out the functions to maintain homeostasis between physical and psychological stress. There are a few reports demonstrating that the basal serum cortisol level was below average in CFS patients [35]. In the present study, poly I:C treatment led to a remarkable decline of mouse serum corticosterone level. PRP elevated the serum corticosterone level in a dose-dependent manner, suggesting that it can modulate the function of HPA axis under the condition of chronic fatigue. 


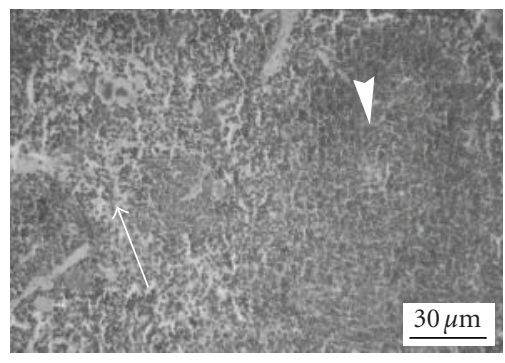

Normal

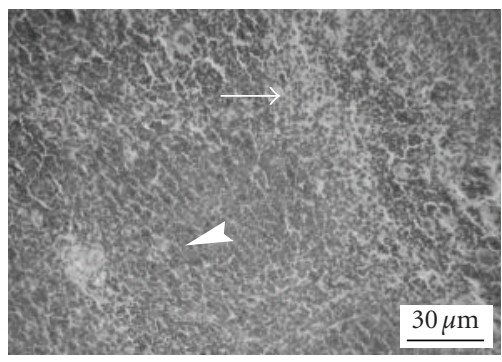

Control

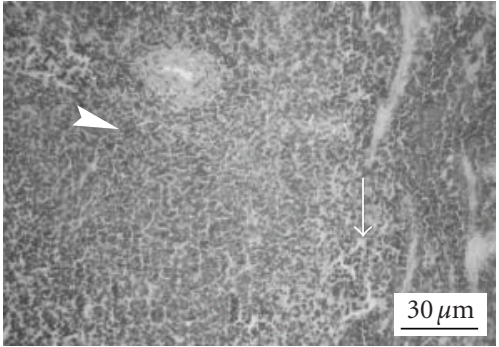

PRP $100 \mathrm{mg} / \mathrm{kg}$

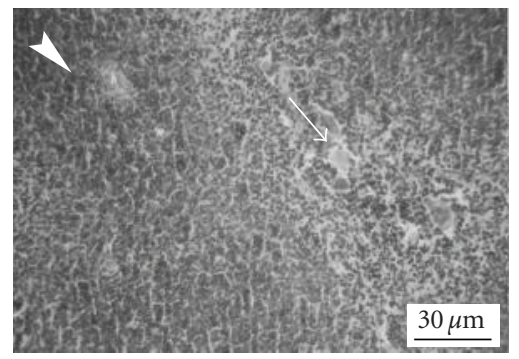

PRP $200 \mathrm{mg} / \mathrm{kg}$

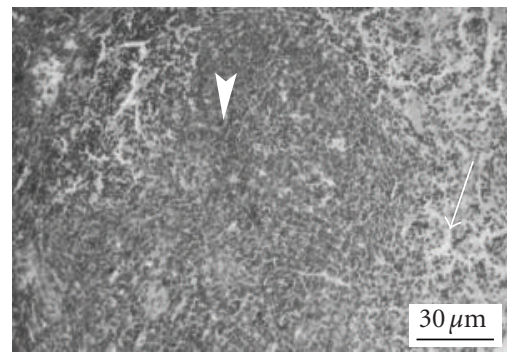

PRP $400 \mathrm{mg} / \mathrm{kg}$

FIGURE 8: Representative histological changes in spleens (hematoxylin and eosin, H\&E, $\times 100$ ). Spleens were removed on Day 14 after poly I:C injection. Numbers of splenic corpuscles and periarterial lymphatic sheaths, splenic sinusoid and splenic cord size were evaluated.

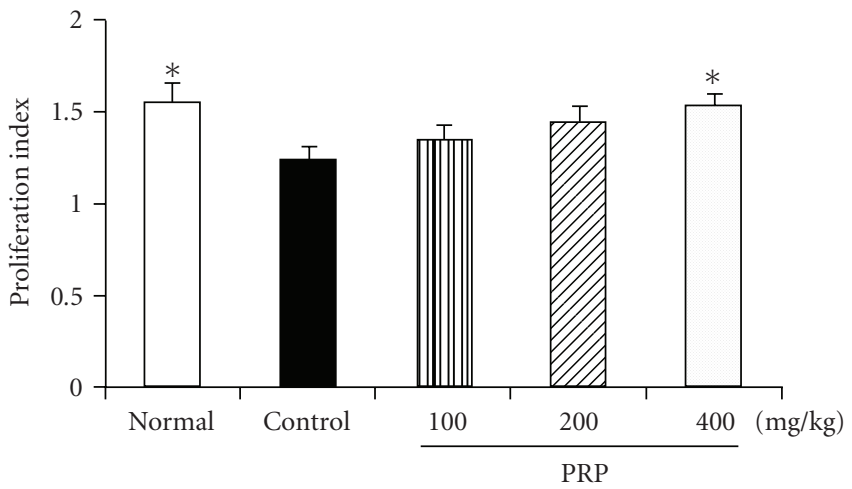

FIGURE 9: Effect of PRP on T lymphocyte proliferation of mice induced by Con A. PRP was administered orally from 3 days before poly I:C injection for 17 days. Splenocytes of mice were treated with or without mitogen Con A on Day 14 after injection of poly I:C. The proliferation ability was evaluated by MTT assay. Data are expressed as means $\pm \operatorname{SEM}(n=6) .{ }^{*} P<.05$ versus control.

CFS patients have specific immune dysfunction profiles characterized by activation of lymphoid populations but suppression of some immune responses [36, 37]. The immune system of CFS patients reacts as if it is continuously combating an infection no matter whether an infectious agent is actually present at the time. But when the patients are challenged with stressors such as infections, immune responses may be blunted due to the production of anti-inammatory cytokines [38]. Mihaylova et al. [39] indicated that this pattern of dysfunction comprised a hyperinammatory resting state and targeted immunosuppression of responses. Substantial evidence has suggested that most of CFS patients have one or more immunological abnormalities related to infectious disorders [40]. In the present study, poly I:C led to a significant increase of both weights and lymphocyte numbers in thymuses and spleens, two important immune organs, suggesting that it might induce a persistent status of immune activation in mice. Moreover, T lymphocyte, an important effector cell in acquired immunity, can be divided into two subclasses, $\mathrm{CD} 4^{+} \mathrm{T}$ cells and $\mathrm{CD} 8^{+} \mathrm{T}$ cells. Of which, $\mathrm{CD}^{+} \mathrm{T}$ cells assist and induce the activation of $\mathrm{T}$ cells and $\mathrm{B}$ cells, while $\mathrm{CD}^{+} \mathrm{T}$ cells impede the activated $\mathrm{B}$ cells producing antibody. The $\mathrm{CD} 4^{+} / \mathrm{CD} 8^{+}$ratio is an important indicator for assessing the function of cell-mediated immunity. Patients with autoimmune diseases have high $\mathrm{CD}^{+} / \mathrm{CD}^{+}$ratio in their blood, indicating that imbalance between $\mathrm{T}$ lymphocyte subclasses could impair the immune system and result in diseases. Generally, poly $\mathrm{I}: \mathrm{C}$ is recognized by toll-like receptor 3 located at the antigen presenting cells (APC). The ligand-receptor recognition leads to IFN- $\alpha / \beta$ production, followed by antigen-specific $\mathrm{T}$ cell activation and differentiation into effector cells. In 


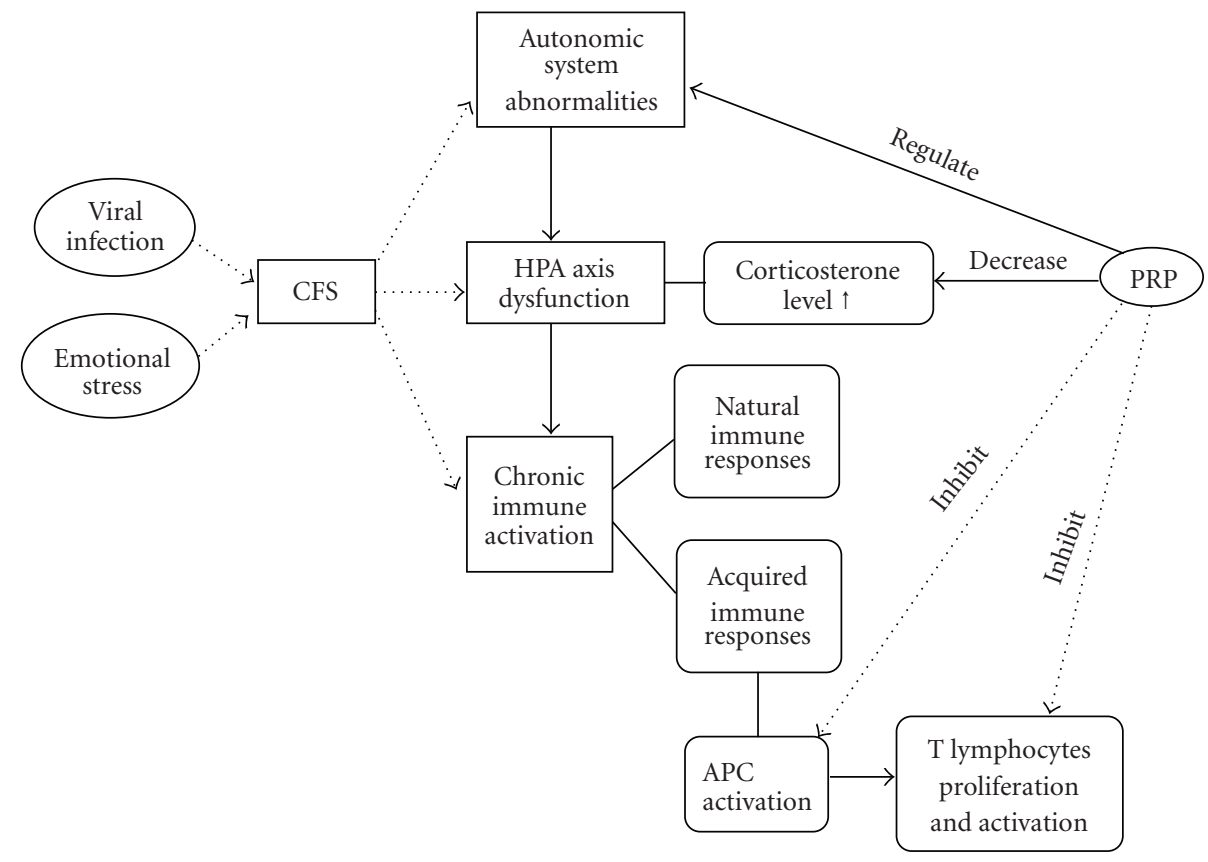

FIGURE 10: The hypothetical mechanisms of PRP against CFS in views of neurological, endocrine and immune modulation.

the present study, poly I:C led to a remarkable increase of $\mathrm{CD}^{+} / \mathrm{CD}^{+}$ratio in peripheral blood of mice by upregulating $\mathrm{CD}^{+}{ }^{+} \mathrm{T}$ cells and down-regulating $\mathrm{CD} 8^{+} \mathrm{T}$ cells, which further demonstrates that poly I:C could induce chronic immune activation, a typical pathological feature of CFS patients. In addition, T lymphocytes derived from spleens of poly I:C-treated mice showed hyporesponsiveness to the stimulation of Con A, indicating that poly I:C actually induced a suppression of immune responses. PRP significantly ameliorate the immunological anomalies caused by poly I:C through down-regulating spleen index, lymphocyte numbers and $\mathrm{CD} 4^{+} / \mathrm{CD}^{+}$ratio in the peripheral blood as well as reversing the hyporesponsiveness of $\mathrm{T}$ cells in spleens.

In conclusion, intraperitoneal injection of poly I:C would lead to a chronic fatigue status in mice, as mainly demonstrated by persistent decrease of forced swimming time and spontaneous activity, which was accompanied by neuroendocrine and immunological abnormalities. PRP effectively alleviated the chronic fatigue, and showed a potential preventive and therapeutic effect for human CFS (Figure 10).

\section{Acknowledgment}

This research was partially supported by the National Innovative Research Plan for Undergraduate Students of China.

\section{References}

[1] K. Fukuda, S. E. Straus, I. Hickie, M. C. Sharpe, J. G. Dobbins, and A. Komaroff, "The chronic fatigue syndrome: a comprehensive approach to its definition and study," Annals of Internal Medicine, vol. 121, no. 12, pp. 953-959, 1994.
[2] S. D. Siegel, M. H. Antonia, M. A. Fletcher, K. Maher, M. C. Segota, and N. Klimas, "Impaired natural immunity, cognitive dysfunction, and physicalsymptoms in patients with chronic fatigue syndrome: preliminary evidence for a subgroup?" Journal of Psychosomatic Research, vol. 60, pp. 559-566, 2006.

[3] M. K. Pincus-Knackstedt, R. A. Joachim, S. M. Blois et al., "Prenatal stress enhances susceptibility of murine adult offspring toward airway inflammation," The Journal of Immunology, vol. 177, no. 12, pp. 8484-8492, 2006.

[4] F. P. de Lange, J. S. Kalkman, G. Bleijenberg, P. Hagoort, J. W. M. van der Meer, and I. Toni, "Gray matter volume reduction in the chronic fatigue syndrome," NeuroImage, vol. 26, no. 3, pp. 777-781, 2005.

[5] T. Y. Segal, P. C. Hindmarsh, and R. M. Viner, "Disturbed adrenal function in adolescents with chronic fatigue syndrome," Journal of Pediatric Endocrinology and Metabolism, vol. 18, no. 3, pp. 295-301, 2005.

[6] N. G. Klimas and A. O. Koneru, "Chronic fatigue syndrome: inflammation, immune function, and neuroendocrine interactions," Current Rheumatology Reports, vol. 9, no. 6, pp. 482-487, 2007.

[7] M. Meeus, J. Nijs, and K. D. Meirleir, "Chronic musculoskeletal pain in patients with the chronic fatigue syndrome: a systematic review," European Journal of Pain, vol. 11, no. 4, pp. 377-386, 2007.

[8] L. D. Devanur and J. R. Kerr, "Chronic fatigue syndrome," Journal of Clinical Virology, vol. 37, no. 3, pp. 139-150, 2006.

[9] T. Katafuchi, T. Kondo, T. Yasaka, K. Kubo, S. Take, and M. Yoshimura, "Prolonged effects of polyriboinosinic:polyribocytidylic acid on spontaneous running wheel activity and brain interferon- $\alpha$ mRNA in rats: a model for immunologically induced fatigue," Neuroscience, vol. 120, no. 3, pp. 837-845, 2003. 
[10] R. Chen, J. Moriya, J. I. Yamakawa, T. Takahashi, and T. Kanda, "Traditional Chinese Medicine for chronic fatigue syndrome," Evidence-Based Complementary and Alternative Medicine, vol. 7, no. 1, pp. 3-10, 2008.

[11] Z. Ni, Y. Mu, and O. Gulati, "Treatment of melasma with Pycnogenol," Phytotherapy Research, vol. 16, no. 6, pp. 567-571, 2002.

[12] C. Kupfersztain, C. Rotem, R. Fagot, and B. Kaplan, "The immediate effect of natural plant extract, Angelica sinensis and Matricaria chamomilla (Climex) for the treatment of hot flushes during menopause," A Preliminary Report of Clinical \& Experimental Obstetrics \& Gynecology, vol. 30, pp. 203-206, 2003.

[13] Y. Wang, D. L. Cai, L. Ma, S. P. Pei, and M. Liu, "Effects of ginsenoside Rg1 on free aminoacids in brain of sports fatigue mice," Parenteral and Enteral Nutrition, vol. 15, pp. 267-270, 2008.

[14] A. J. Hartz, S. Bentler, R. Noyes et al., "Randomized controlled trial of Siberian ginseng for chronic fatigue," Psychological Medicine, vol. 34, no. 1, pp. 51-61, 2004.

[15] Y. Wu, X. Wang, M. Li, and T. C. Compbell, "Effect of Ciwujia (Radix Acanthopanacis senticosus) preparation on exercise performance under constant endurance load for elderly," Wei Sheng Yan Jiu, vol. 27, pp. 421-424, 1998.

[16] F. H. Degenring, A. Suter, M. Weber, and R. Saller, "A randomized double blind placebo controlled clinical trial of a standardized extract of fresh Crataegus berries (Crataegisan) in the treatment of patients with congestive heart failure NYHA II," Phytomedicine, vol. 10, pp. 363-369, 2003.

[17] Y. Li, K. Koike, Q. Che, M. Yamaguchi, and S. Takahashi, "Changes in lactate dehydrogenase and 3-hydroxyacetylCoA dehydrogenase activities in rat skeletal muscle by the administration of Eucommia ulmoides OLIVER leaf with spontaneous running-training," Biological \& Pharmaceutical Bulletin, vol. 22, pp. 941-946, 1999.

[18] V. Darbinyan, A. Kteyan, A. Panossian, E. Gabrielian, G. Wikman, and H. Wagner, "Rhodiola rosea in stress induced fatigue-a double blind cross-over study of a standardized extract SHR-5 with a repeated low-dose regimen on the mental performance of healthy physicians during night duty," Phytomedicine, vol. 7, pp. 365-371, 2000.

[19] K. M. Kim, K. W. Yu, D. H. Kang, and H. J. Suh, "Anti-stress and anti-fatigue effect of fermented rice bran," Phytotherapy Research, vol. 16, no. 7, pp. 700-702, 2002.

[20] D. A. Evans, A. Subramoniam, S. Rajasekharan, and P. Pushpangadan, "Effect of Trichopus zeylanicus leaf extract on the energy metabolism in mice during exercise and at rest," Indian Journal of Pharmacology, vol. 34, no. 1, pp. 32-37, 2002.

[21] N. Ozturk, K. Husnu Can Baser, S. Aydin, Y. Ozturk, and I. Calis, "Effects of Gentiana lutea ssp. symphyandra on the central nervous system in mice," Phytotherapy Research, vol. 16, pp. 627-631, 2002.

[22] A. Singh, P. S. Naidu, S. Gupta, and S. K. Kulkarni, "Effect of natural and synthetic antioxidants in a mouse model of chronic fatigue syndrome," Journal of Medicinal Food, vol. 5, no. 4, pp. 211-220, 2002.

[23] A. C. Logan and C. Wong, "Chronic fatigue syndrome: oxidative stress and dietary modifications," Alternative Medicine Review, vol. 6, no. 5, pp. 450-459, 2001.

[24] C. K. Wong, K. N. Leung, K. P. Fung, P. K. T. Pang, and Y. M. Choy, "Mitogenic and tumor necrosis factor producing activities of Pseudostellaria heterophylla," International Journal of Immunopharmacology, vol. 14, no. 8, pp. 1315-1320, 1992.
[25] J. Li and Y.-Y. Fu, "Effects of IgY, coptis chinensis and radix pseudostellariae on gastric mucous membrane in mice with helicobacter pylori infection," Chinese Journal of Clinical Rehabilitation, vol. 10, no. 31, pp. 78-80, 2006.

[26] Z. Zhang, B. Xu, and Y. Yuan, "Study on antioxidative activity of the extract from Pseudostellaria heterophylla," Chinese Journal of Clinical Pharmacy, vol. 26, pp. 148-149, 2006.

[27] J. Cai, X. Li, X. Chen, L. Zheng, and J. Lin, "The immune effects of crude extract of Pseudostellaria polysaccharide in mice," Fujian University of Traditional Chinese Medicine, vol. 15, pp. 33-35, 2005.

[28] W. S. Sheng, S. Hu, A. Lamkin, P. K. Peterson, and C. C. Chao, "Susceptibility to immunologically mediated fatigue in C57BL/6 versus balb/c mice," Clinical Immunology and Immunopathology, vol. 81, no. 2, pp. 161-167, 1996.

[29] T. Takahashi, F. Yu, S.-J. Zhu et al., "Beneficial effect of Brewers' yeast extract on daily activity in a murine model of chronic fatigue syndrome," Evidence-Based Complementary and Alternative Medicine, vol. 3, no. 1, pp. 109-115, 2006.

[30] X. Q. Wang, T. Takahashi, S. J. Zhu, J. Moraya, S. Saegusa, and J. Yamakawa, "Effect of Hochu-ekki-to (TJ-41), a Japanese herbal medicine, on daily activity in a murine model of chronic fatigue syndrome," Evidence-Based Complementary and Alternative Medicine, vol. 1, pp. 203-206, 2004.

[31] A. Dhir and S. K. Kulkarni, "Venlafaxine reverses chronic fatigue-induced behavioral, biochemical and neurochemical alterations in mice," Pharmacology Biochemistry and Behavior, vol. 89 , no. 4 , pp. 563-571, 2008.

[32] T. Katafuchi, T. Kondo, S. Take, and M. Yoshimura, "Brain cytokines and the 5-HT system during poly I:C-induced fatigue," Annals of the New York Academy of Sciences, vol. 1088, pp. 230-237, 2006.

[33] N. J. Rothwell and S. J. Hopkins, "Cytokines and the nervous system II: actions and mechanisms of action," Trends in Neurosciences, vol. 18, no. 3, pp. 130-136, 1995.

[34] T. Katafuchi, T. Kondo, S. Take, and M. Yoshimura, "Enhanced expression of brain interferon- $\alpha$ and serotonin transporter in immunologically induced fatigue in rats," European Journal of Neuroscience, vol. 22, no. 11, pp. 2817-2826, 2005.

[35] A. J. Cleare, "The HPA axis and the genesis of chronic fatigue syndrome," Trends in Endocrinology and Metabolism, vol. 15, no. 2, pp. 55-59, 2004.

[36] R. R. Dietert and J. M. Dietert, "Possible role for early-life immune insult including developmental immunotoxicity in chronic fatigue syndrome (CFS) or myalgic encephalomyelitis (ME)," Toxicology, vol. 247, no. 1, pp. 61-72, 2008.

[37] E. Barker, S. F. Fujimura, M. B. Fadem, A. L. Landay, and J. A. Levy, "Immunologic abnormalities associated with chronic fatigue syndrome," Clinical Infectious Diseases, vol. 18, no. 1, pp. S136-S141, 1994.

[38] N. G. Klimas, F. R. Salvato, R. Morgan, and M. A. Fletcher, "Immunologic abnormalities in chronic fatigue syndrome," Journal of Clinical Microbiology, vol. 28, no. 6, pp. 1403-1410, 1990.

[39] I. Mihaylova, M. DeRuyter, J. L. Rummens, E. Bosmans, and M. Maes, "Decreased expression of CD69 in chronic fatigue syndrome in relation to in flammatory markers: evidence for a severe disorder in the early activation of T lymphocytes and natural killer cells," Neuroendocrinology Letters, vol. 28, pp. 477-483, 2007.

[40] D. Maquet, C. Demoulin, and J.-M. Crielaard, "Chronic fatigue syndrome: a systematic review," Annales de Readaptation et de Medecine Physique, vol. 49, no. 6, pp. 418-427, 2006. 


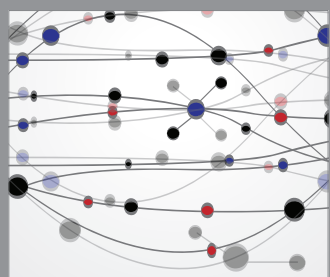

The Scientific World Journal
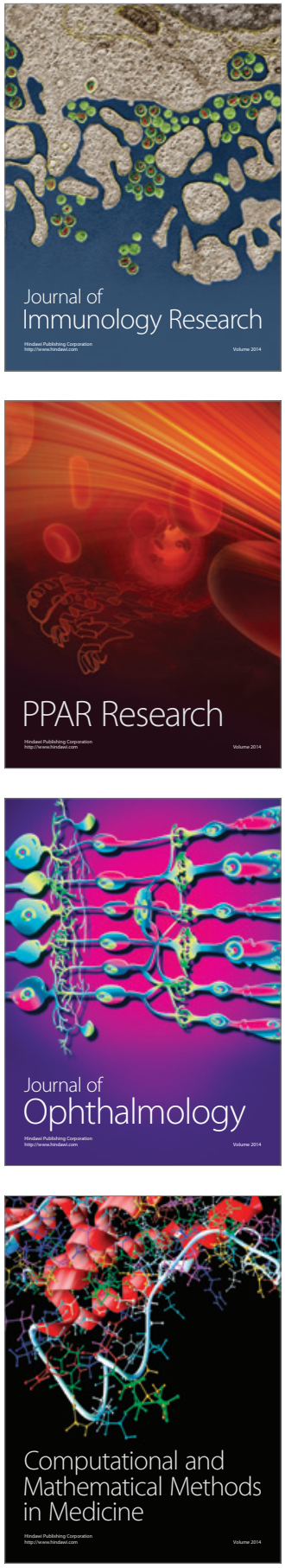

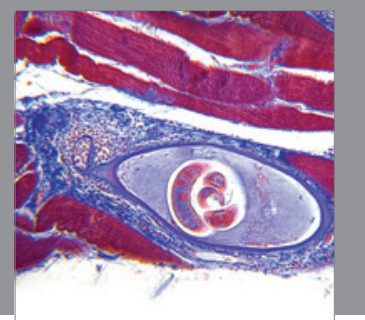

Gastroenterology

Research and Practice
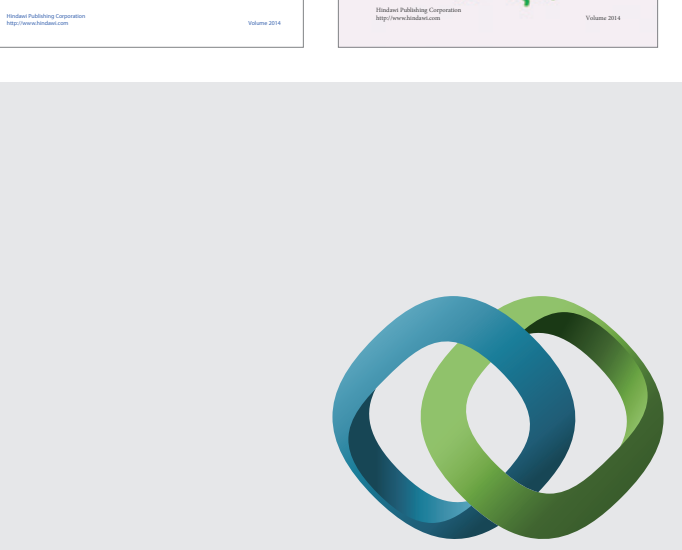

\section{Hindawi}

Submit your manuscripts at

http://www.hindawi.com
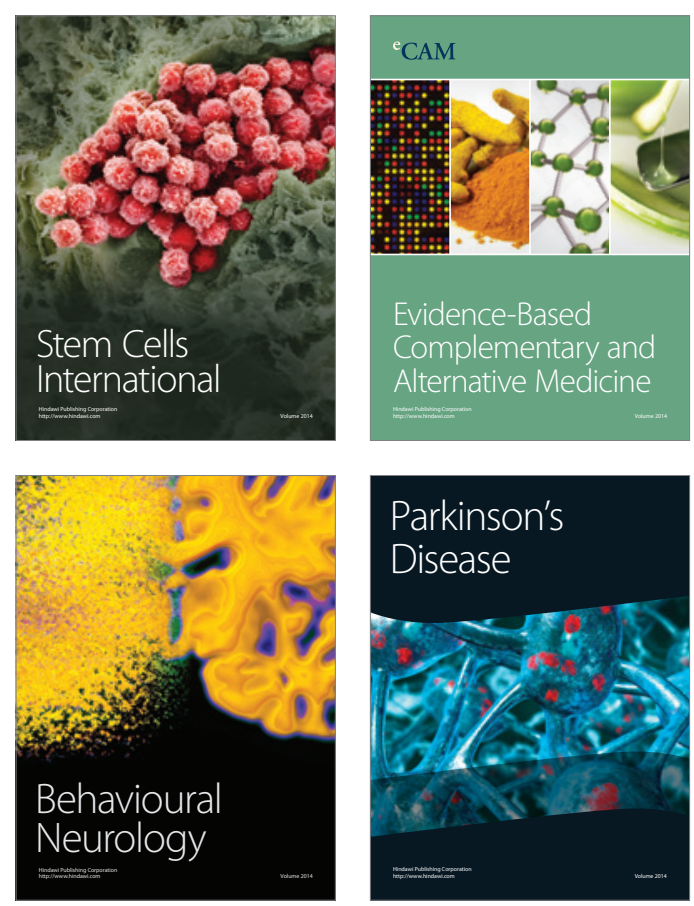

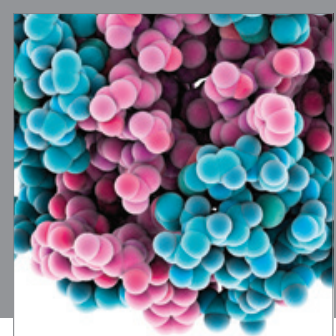

Journal of
Diabetes Research

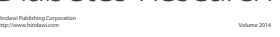

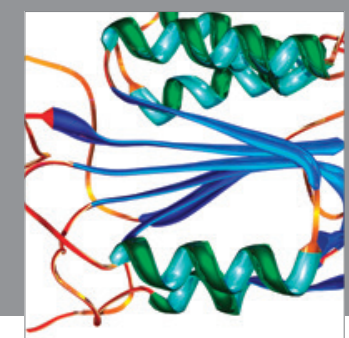

Disease Markers
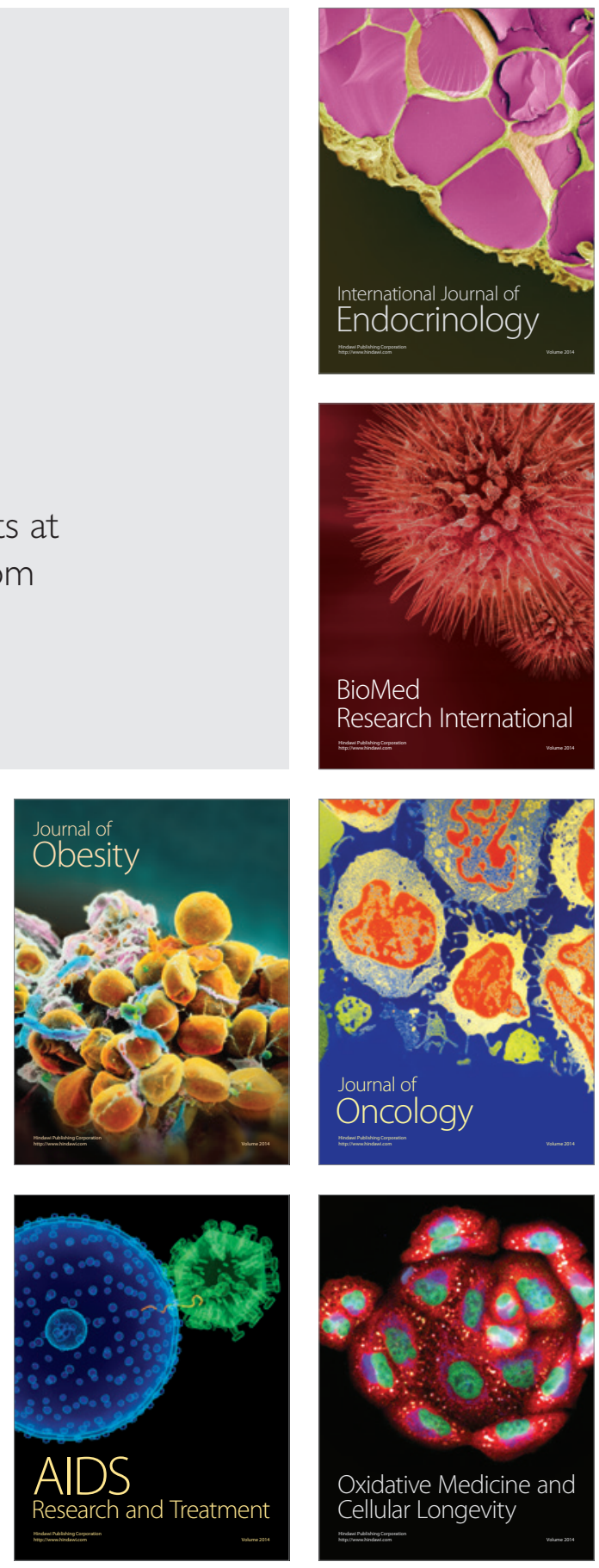